\title{
PENGEMBANGAN HIDROPONIK DRIP SYSTEM PLUS MONITORING VIA LCD DAN WEBSITE
}

\author{
Jimmy Reynaldi \\ Prodi Teknik Otomasi Listrik Industri, Jurusan Teknik Elektro, Politeknik Negeri Jakarta, \\ Jl. prof.Dr.GA Siwabessy, Kampus Baru UI Depok 16425 \\ e-mail : jimmyreynaldi02@gmail.com
}

\begin{abstract}
To maintain the quality of hydroponic plants, it is necessary to check parameters such as $p H$, temperature, and nutrient levels in the water. In order not to make it difficult for humans, inspections can be carried out in real time for 24 hours through a microcontroller-based monitoring system. The monitoring process uses an Arduino Mega $2560+$ ESP8266 microcontroller and data communication is carried out via wireless media. The nutrient water $p H$ reading system uses a $p H$ sensor, the water temperature reading uses the DS18B20 sensor, the ppm reading uses the TDS sensor, the water level reading uses the Ultrasonic HC$S R 04$ sensor and the battery voltage reading uses a DC voltage sensor. As a result, a microcontroller-based monitoring system can function properly to monitor $\mathrm{pH}$, temperature, and nutrient levels in water. This is evidenced by the appearance of measurement values on LCD displays and websites.
\end{abstract}

\section{Keywords: Hydroponic Drip System, Arduino Mega + ESP8266, Website, Sensor}

\begin{abstract}
ABSTRAK
Untuk menjaga kualitas tanaman hidroponik perlu dilakukan pemeriksaan parameter seperti $\mathrm{pH}$, suhu, dan kadar nutrisi dalam air. Agar tidak menyulitkan manusia, pemeriksaan dapat dilakukan secara real time selama 24 jam melalui sistem monitoring berbasis mikrokontroler. Proses monitoring menggunakan mikrokontroler Arduino Mega 2560 + ESP8266 dan komunikasi data yang dilakukan melalui media nirkabel. Sistem pembacaan $\mathrm{pH}$ air nutrisi menggunakan sensor $\mathrm{pH}$, pembacaan suhu air menggunakan sensor DS18B20, pembacaan ppm menggunakan sensor TDS, pembacaan level air menggunakan sensor Ultrasonic HC-SR04 dan pembacaan tegangan baterai menggunakan sensor tegangan DC. Hasilnya, sistem monitoring berbasis mikrokontroler dapat berfungsi dengan baik untuk memonitor parameter $\mathrm{pH}$, suhu, dan kadar nutrisi dalam air. Hal ini dibuktikan dengan tampilnya nilai pengukuran pada display LCD dan website.
\end{abstract}

Kata Kunci: Hidroponik Drip System, Arduino Mega + ESP8266, Website, Sensor

\section{PENDAHULUAN}

Hidroponik drip sistem adalah sistem menanam tanaman menggunakan sistem irigasi tetes (drip irrigation system) untuk mengalirkan nutrisi ke wilayah perakaran melalui selang irigasi dengan menggunakan dripper yang diatur waktunya dengan timer [1], [2]. Media tanam sistem ini adalah batu apung, sekam bakar, zeolit, atau cocopeat (sabut kelapa), yang berfungsi sebagai tempat akar berkembang dan memperkokoh kedudukan tanaman [3],[4]. Nutrisi hidroponik disimpan di wadah.

Parameter air yang perlu diperhatikan agar menghasilkan kualitas tanaman yang baik adalah pH air, part per million ( $p p m$ ) yaitu kadar nutrisi untuk tanaman dan suhu air. Selama ini monitoring parameter tersebut dilakukan secara manual sehingga memakan waktu yang lama. Untuk memudahkan dalam memonitor parameter 


\section{Pengembangan Hidroponik Drip System Plus Monitoring}

tersebut kami membuat sistem monitoring berbasis mikrokontroler yang dapat mengukur parameter air secara real time selama 24 jam dan hasil pengukuran dapat dilihat pada display LCD pada panel dan website.

Sistem monitoring berbasiskan mikrokontroler dan IoT telah banyak dilakukan oleh peneliti antara lain pada aplikasi monitoring kualitas air pada perikanan [5], kualitas air pada limbah [6],[7], dan $\mathrm{pH}$ pada sistem aquaponik [8]-[10]. Namun belum ada yang menggunakan sistem monitoring parameter air untuk aplikasi hidroponik drip system.

Oleh karena itu, dalam artikel ini kami merancang bangun hidroponik drip sistem plus sistem monitoringnya. Sistem ini memilki komponen utama yaitu hidroponik drip system yang dilengkapi oleh sensor-sensor sebagai komponen untuk membaca situasi. Monitoring sistem menggunakan Arduino Mega + ESP8266 dan memakai website berbasis HTML untuk membaca hasil Sensor.

Sensor-sensor yang digunakan antara lain sensor $p H$, level air, TDS, DS18B20 (sensor suhu), dan sensor tegangan. Fungsi dari sensor $p H$ adalah untuk mengukur $p H$ air yang digunakan untuk mencampur air dengan nutrisi. $p H$ air akan disesuaikan oleh larutan kalibrasi $p H$. Setelah $p H$ sudah sesuai maka akan dilakukan pencampuran larutan nutrisi sampai ppm sesuai yang akan dibaca oleh sensor TDS. $p H$ air dan campuran nutrisi, jika sudah sesuai air dapat digunakan untuk pemberian nutrisi pada tanaman hidroponik drip system tersebut. Pemberian nutrisi tanaman pada drip system menggunakan pompa nonstop 24 jam untuk mengaliri air nutrisi agar nutrisi tanaman terpenuhi. Pada sistem ini menggunakan sensor ultrasonic sebagai pengukur level air dan sensor tegangan sebagai pengukur tegangan baterai, ketika air nutrisi hampir habis maka buzzer akan aktif dan tegangan baterai ketika mendekati kosong LED akan off sebagai indikator. Sistem suplai listrik pada alat ini juga menggunakan power supply sebagai cadangan listrik ketika baterai telah kosong.

\section{METODE PENELITIAN}

Proses Monitoring Hidroponik Drip System Berbasis Website dapat dilihat pada Gambar 1. Pada sisi input terdapat 5 sensor yaitu terdiri dari Sensor Tegangan $D C$ untuk mengukur tegangan baterai, Sensor TDS untuk mengukur kadar nutrisi (ppm) pada bak air nutrisi hidroponik, Sensor Ultrasonic intuk mengukur level air pada bak nutrisi, Sensor DS18B20 untuk mengukur suhu air pada bak nutrisi, dan Sensor $p H$ untuk mengukur $p H$ air bak nutrisi hidroponik. Pada sisi Proses yang digunakan menggunakan Arduino Mega $2560+$ ESP8266 sebagai pengontrol sistem dan mendapat suplai listrik dari Solar Cell yang disimpan ke baterai atau menggunakan suplai Power Supply. Output sistem ini meliputi Led sebagai indikator baterai, relay digunakan untuk menyalakan pompa, LCD $20 X 4$ untuk menampilkan data sensor, buzzer sebagai indikator level air bak nutrisi dan parameter sensor akan masuk ke website.

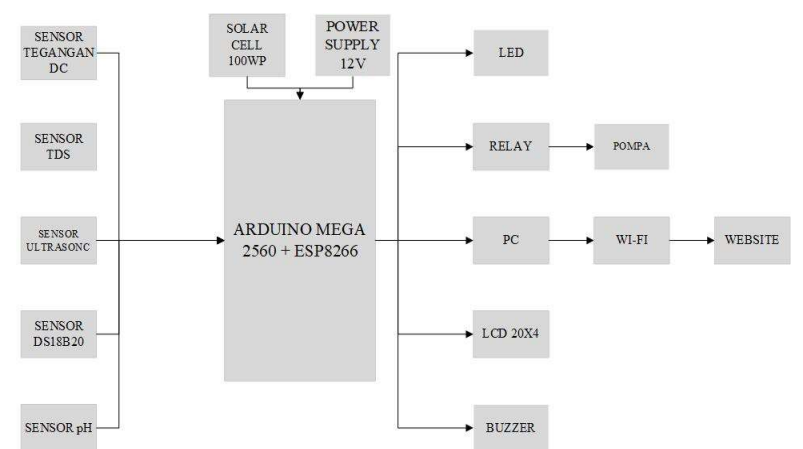

Gambar 1. Diagram Blok sistem monitoring

Langkah - langkah penelitian yang dilakukan adalah:

1. Mengambil data pengukuran sensor seperti sensor tegangan DC, TDS, ultrasonic, DS18B20 dan sensor $\mathrm{pH}$.

2. Melakukan Percobaan dengan 2 suplai yaitu suplai listrik dari Baterai dan Power Supply.

3. Menghubungkan data sensor dari Mikrokontroler ke webstie.

4. Membandingkan data sensor pada LCD 20X4 dengan website.

5. Menganalisa sistem setelah semua parameter saling terhubung.

Desain alat hidroponik drip sistem terlihat pada Gambar 2 dan alat yang sudah jadi terlihat pada Gambar 3.

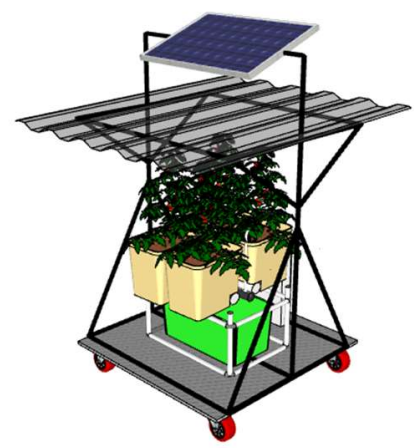

Gambar 2. Desain Alat 


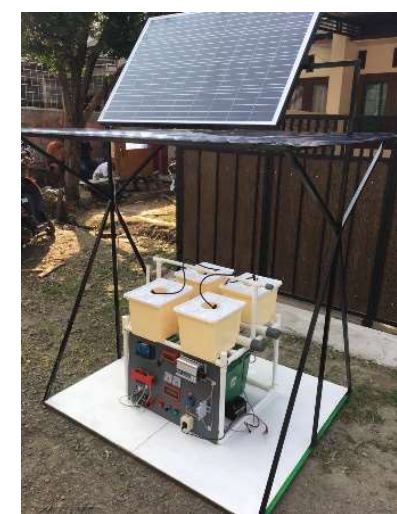

Gambar 3. Alat yang sudah jadi

Wiring diagram sensor dan mikrokontroler terlihat ada Gambar 4 dan peralatan input/ output terlihat pada Tabel 1 .

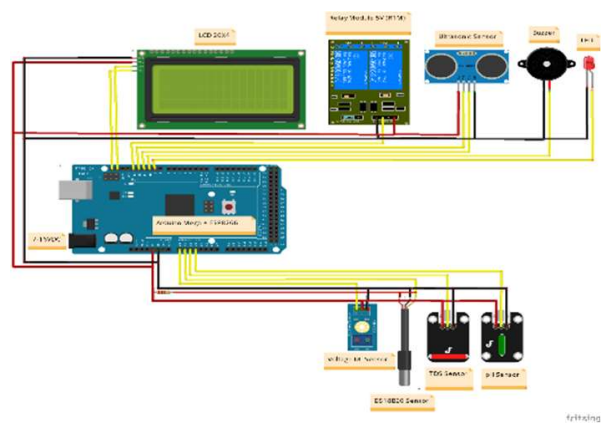

Gambar 4. Wiring Sensor dan Mikrokontoller

Tabel 1. I/O sistem

\begin{tabular}{ccl}
\hline \multicolumn{2}{c}{ I/O Arduino Mega $2560+$ ESP 8266} & I/O \\
\hline Input/Output & Address & Status \\
Sensor $p H$ & $\mathrm{~A} 0$ & Input \\
Sensor TDS & $\mathrm{A} 1$ & Input \\
Sensor DS18B20 & $\mathrm{A} 2$ & Input \\
Sensor Tegangan DC & $\mathrm{A} 3$ & Input \\
LCD & SDA \& SCL & Output \\
Relay & 13 & Output \\
Sensor Ultrasonic & $11 \& 12$ & Input \\
Buzzer & 10 & Output \\
LED & 9 & Output \\
\hline
\end{tabular}

\section{HASIL DAN PEMBAHASAN}

\section{a. Prosedur Pengujian}

Prosedur pengujian yang dilakukan dengan mengoperasikan pemrograman Arduino IDE menghubungkan dengan hardware Arduino Mega $2560+$ ESP8266 ke PC/Laptop. Prosedur yang dilakukan sebagai berikut :

1. Hubungkan kabel USB dari Arduino Mega $2560+$ ESP8266 ke PC/Laptop.

2. Buka aplikasi Arduino IDE seperti pada Gambar 5.

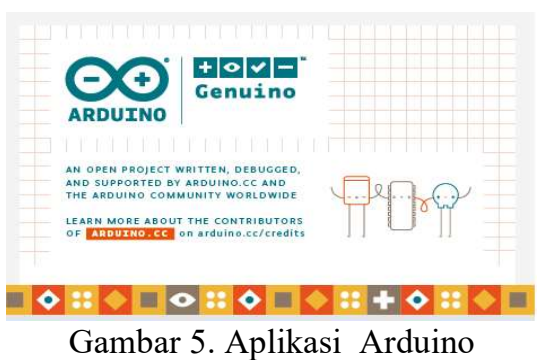

3. Masukan program untuk Module ESP8266 seperti pada Gambar 6. Lalu sesuaikan SSID dan Password sesuai router $W i-F i$ yang digunakan.

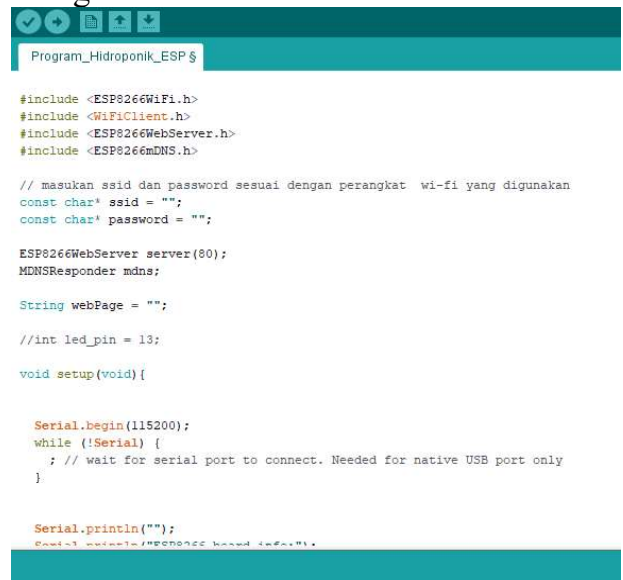

Gambar 6. Tampilan Halaman Arduino Program ESP8266

4. Setelah program telah dimasukan pastikan port Arduino dan Board telah sesuai. Pilih port yang tersedia dan pilih Board "Generic ESP8266 Module” seperti pada Gambar 7.

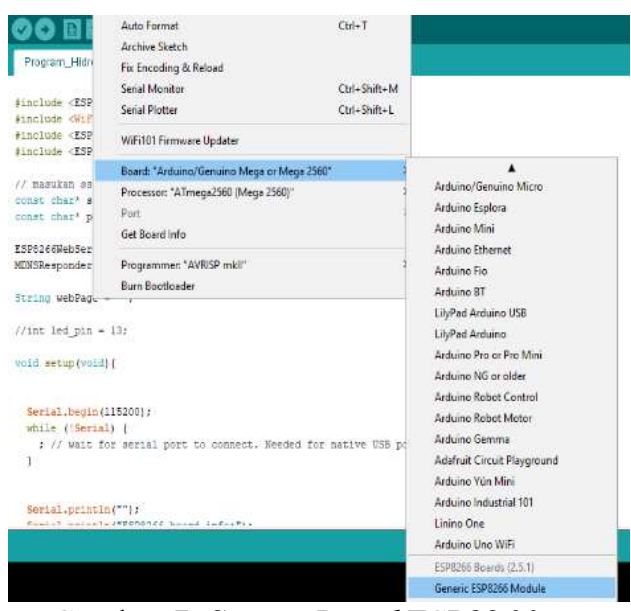

Gambar 7. Setting Board ESP8266

5. Pada bagian hardware Arduino Mega $2560+$ ESP8266 sebelum di upload aktifkan switch 5, 6 dan 7 untuk upload program ESP8266.

6. Lalu Upload program seperti pada Gambar 8. 


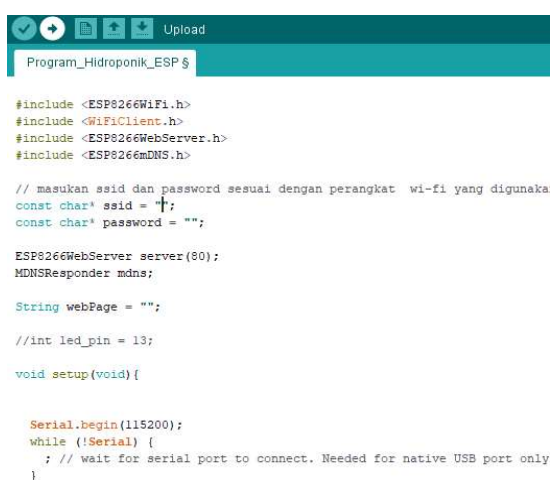

Gambar 8. Upload Program ESP8266

7. Setelah di upload lalu nonaktifkan switch 7. Lalu buka Serial Monitor untuk mendapatkan IP address seperti pada Gambar 9 untuk membuka Website HTML.

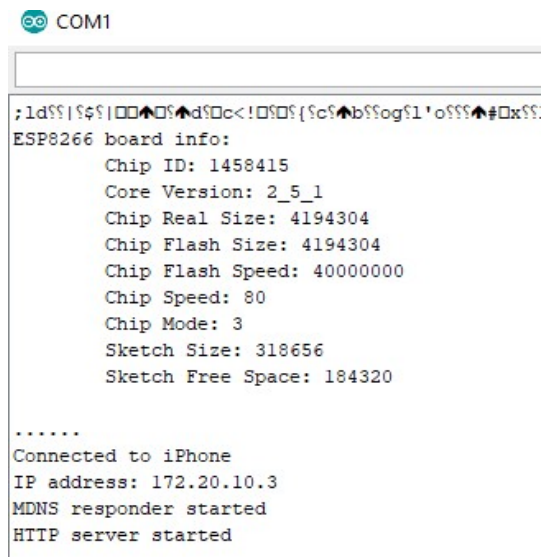

Gambar 9. Com Port Arduino Menampilkan IP Address Website

8. Copy dan paste IP address ke Browser/google untuk memastikan server terhubung atau tidak seperti pada Gambar 10.

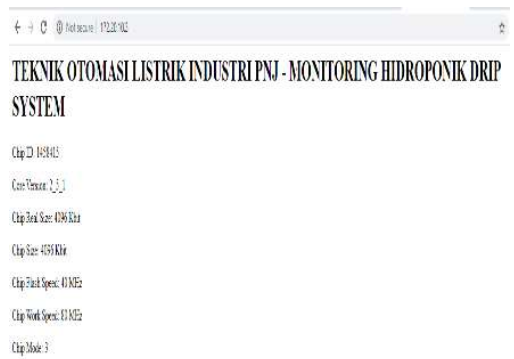

Gambar 10. Tampilan Website HTML

9. Langkah selanjutnya adalah memasukan program untuk Module Arduino seperti pada Gambar 11.

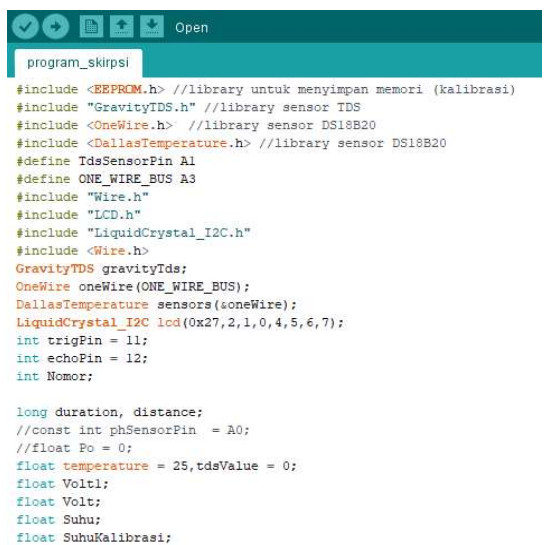

Gambar 11. Tampilan Halaman Arduino Program Arduino

10. Pilih Board untuk Arduino yaitu Board "Arduino/Genuino Mega or Mega 2560" sepeti pada Gambar 12 .

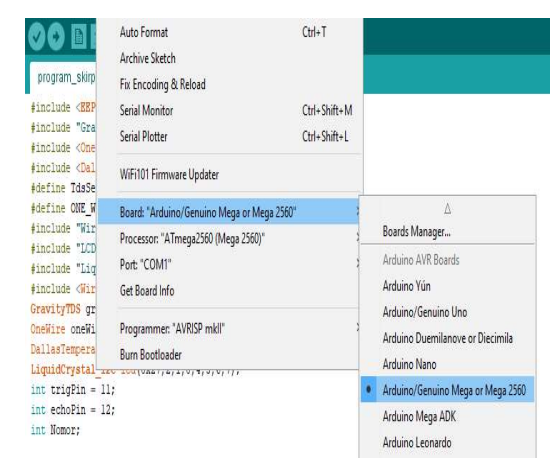

Gambar 12. Setting Board Arduino Mega

11. Setelah langkah 10 dilakukan nonaktifkan swtich hardware Arduino Mega 5, 6 dan aktifkan swtich 1, 2, 3 dan 4.

12. Lalu upload Program seperti pada Gambar 13.

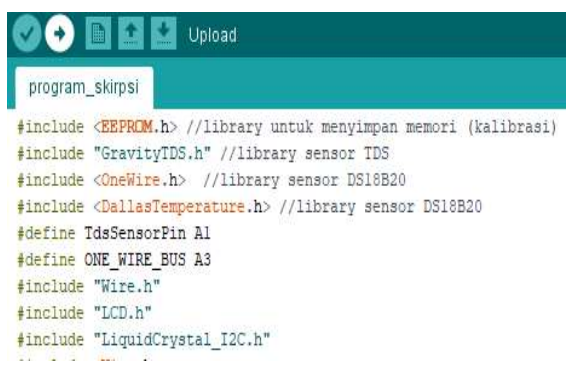

Gambar 13. Upload Program Arduino

13. Jika sudah di upload nonaktifkan switch

14. Lalu refresh website yang telah dibuka pada browser/google maka data sensor akan terbaca dalam 1 detik seperti pada Gambar 14. 


\section{Pengembangan Hidroponik Drip System Plus Monitoring}

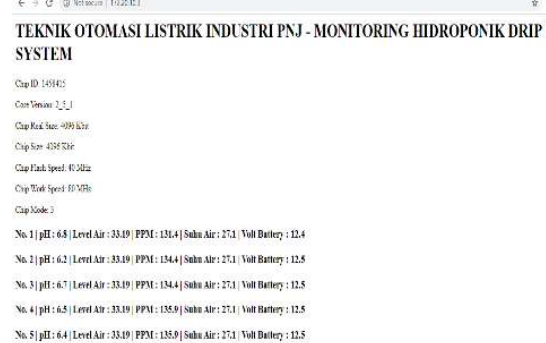

Gambar 14. Data Sensor Hidroponik Drip System Pada Website HTML

15. Data sensor akan terlihat pada LCD 20X4 seperti pada Gambar 15 .

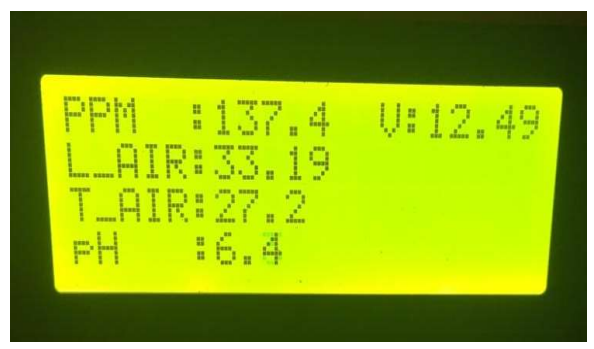

Gambar 15. Data Sensor Hidroponik Drip System Pada LCD 20X4

\section{b. Data Pengukuran}

Data yang dilakukan mengambil 5 buah data sensor dan 2 buah indikator. Lima sensor diantaranya sensor DS18B20 sebagai pengukur suhu air nutrisi, sensor $T D S$ sebagai alat ukur $p p m$ air nutrisi, sensor Tegangan $D C$ sebagai pengukur tegangan baterai, sensor ultrasonic sebagai pengukur level air, sensor $\mathrm{pH}$ sebagai pengukur pH air, indikator buzzer ketika level air dibawah $20 \%$ dan $L E D$ sebagai tanda tegangan baterai ketika baterai dibawah 11.5 Volt.

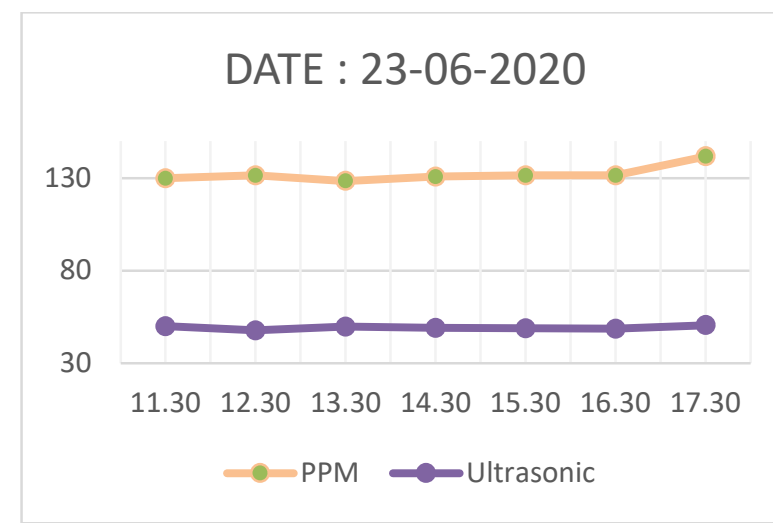

Gambar 16. Pengujian Hari Ke- 1 Data Ke- 1

Pada pengujian seperti pada Gambar 16 terlihat grafik sensor TDS ( $\mathrm{ppm}$ ) dan Ultrasonic (level air). Pengukuran sensor ini dilakukan pada pukul 11.30 sampai 17.30 WIB. Data menunjukan tidak ada perubahan nilai pada sensor tersebut dan begitu stabil. Indikator buzzer level air tidak aktif karena level air tetap berada diatas $20 \%$.

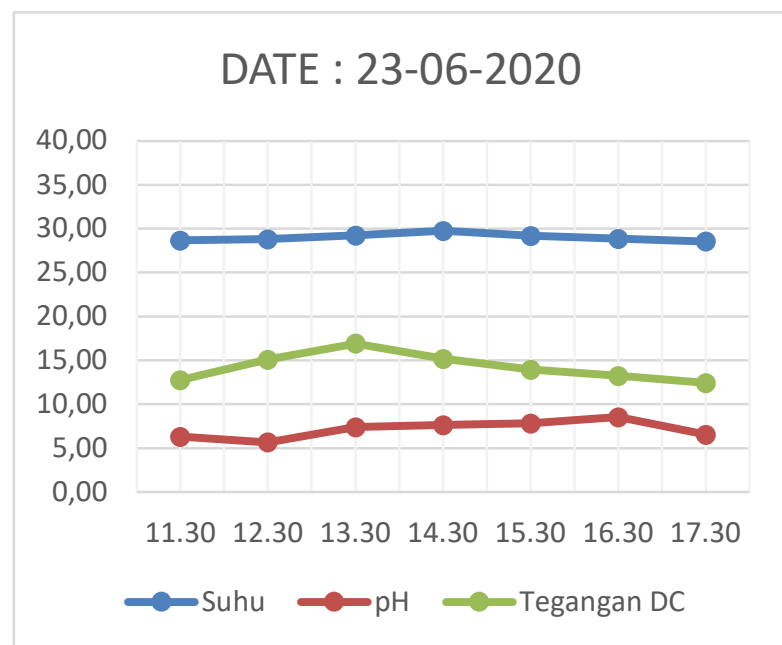

Gambar 17. Pengujian Hari Ke- 1 Data Ke- 2

Pada pengujian seperti pada Gambar 17 terlihat grafik sensor Suhu, $p H$ dan sensor tegangan $D C$. Pada sensor suhu terlihat suhu meningkat pada pukul 13.30 hal ini dikarenakan cuaca panas dan mengakibatkan suhu lingkungan naik. Pada sensor tegangan $D C$ terlihat tegangan naik pada pukul 11.30 sampai 15.30 dikarenakan intensitas cahaya pada jam tersebut meningkat sehingga tegangan yang dihasilkan panel surya menuju baterai meningkat, dan pada pukul 16.30 sampai 17.30 tegangan menurun karena waktu tersebut intensitas cahaya matahari mulai menurun sehingga tegangan ke baterai menurun. Sensor $p H$ mengalami perubahan nilai dikarenakan sensor mengalamni error ketika suhu air meningkat dan diakibatkan pompa air membuat noise pada bak nutrisi sehingga error pada sensor $\mathrm{pH}$ meningkat. Indikator $L E D$ untuk tegangan baterai tetap aktif karena tegangan baterai tetap berada ditas 11.5 Volt.

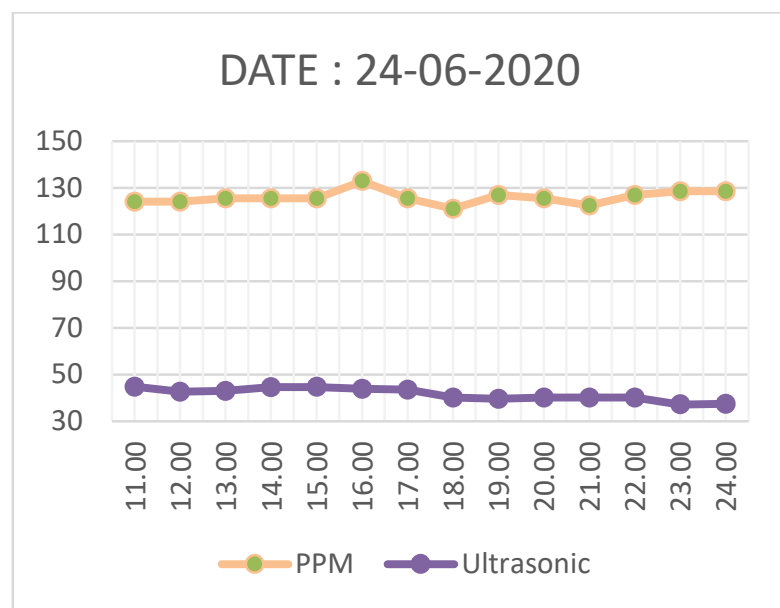

Gambar 18. Pengujian Hari Ke- 2 Data Ke- 1 


\section{Pengembangan Hidroponik Drip System Plus Monitoring}

Pada pengujian seperti pada Gambar 18 terlihat grafik sensor TDS ( $\mathrm{ppm}$ ) dan Ultrasonic (level air). Pengukuran sensor ini dilakukan pada pukul 11.00 sampai 00.00 WIB. Data menunjukan bahwa nilai sensor TDS (ppm) tidak stabil hal ini dikarenakan kualitas sensor yang tidak cukup baik dalam melakukan pengukuran. Pada sensor ultrasonic, level air stabil dan mengurang seiring waktu dikarenakan air nutrisi terus mengalir keatas permukaan menyiram tanaman selama 24 jam. Indikator buzzer level air tidak aktif karena level air tetap berada diatas $20 \%$.

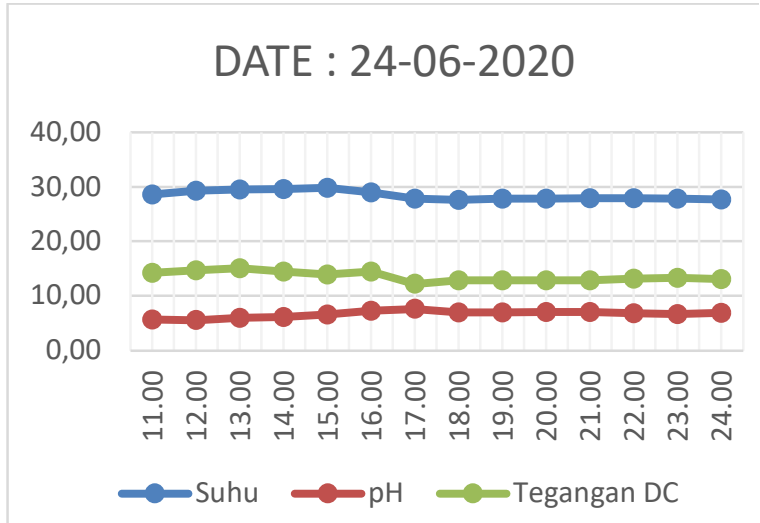

Gambar 19. Pengujian Hari Ke- 2 Data Ke- 2

Pada pengujian seperti pada Gambar 19 terlihat grafik sensor Suhu, $p H$ dan sensor tegangan $D C$. Data sensor pada grafik ini cukup stabil tidak ada perubahan nilai secara signifikan. Indikator $L E D$ untuk tegangan baterai tetap aktif karena tegangan baterai tetap berada ditas 11.5 Volt.

\section{c. Hasil perbandingan data sensor $L C D 20 X 4$ dengan website berbasis $H T M L$}

Hasil tampilan data sensor parameter air pada display LCD dan website terlihat pada Gambar 20 dan 21.

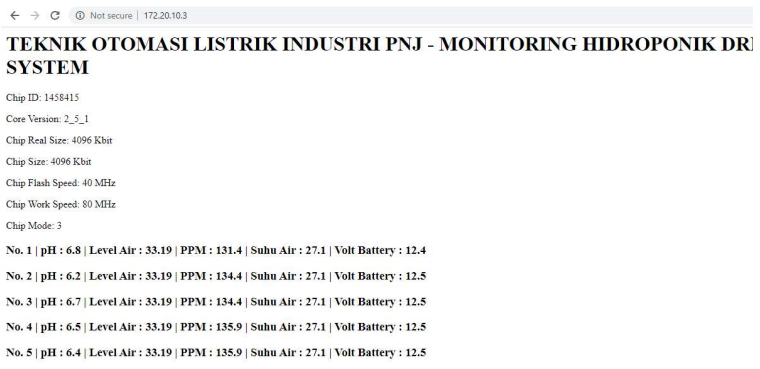

Gambar 20. Hasil Data Sensor Pada Website

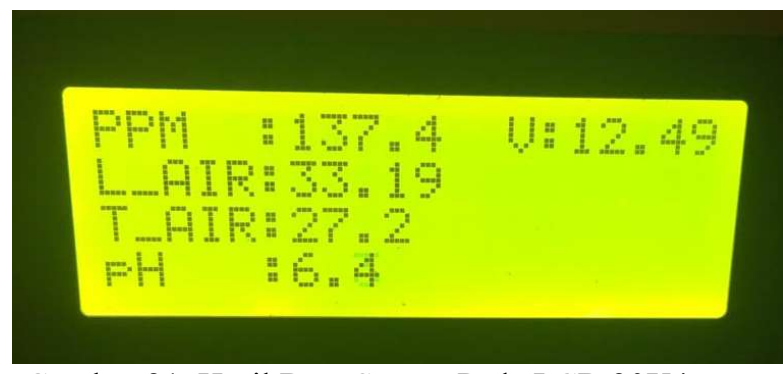

Gambar 21. Hasil Data Sensor Pada LCD 20X4

Berdasarkan Gambar 20 dan Gambar 21 terlihat bahwa data yang ditampilkan LCD $20 X 4$ dan website tidak ada perbedaan nilai. Sehingga hal ini membuktikan bahwa sistem yang kami buat telah berfungsi dengan baik.

\section{KESIMPULAN}

Rancangn bangun hidroponik drip sytem puls sistem monitoringnya telah berhasil dan berfungsi dengan baik. Namun sistem ini masih ada kelemahannya. Sehingga perlu dikembangkan lebih lanjut. Adapun saran untuk pengembangan selanjutnya adalah :

1. Perlu dibuatnya sistem kontrol agar alat ini dapat menstabilkan $p H$ air, $p p m$, pengisian air secara otomatis tanpa dilakukan secara konvensional.

2. Perlu dibuatnya pendinginan agar suhu air pada bak penampungan tidak panas karena dapat membuat error sensor $p H$ dan merusak air nutrisi.

3. Pada website perlu pengembangan seperti tampilan website yang lebih menarik dan dibuat aplikasi mobile sehingga memudahkan pengguna dalam melakukan pengontrolan tanpa harus melalui browser.

4. Pada sisi suplai perlu dibuat nya sistem otomatis ketika baterai kosong dapat secara otomatis berpindah dalam mode power supply.

\section{DAFTAR PUSTAKA}

[1] T. E. Tallei and I. F. M. R. A. A. Adam, Hidroponik Untuk Pemula, no. January. 2018.

[2] B. Prasetya, A. B. Setiawan, and B. F. Hidayatulail, "Pengaturan $\mathrm{pH}$ Media Tanam Dan Suhu Tanaman Tomat Pada Sistem Hidroponik Drip Menggunakan Fuzzy Mamdani," SinarFe7, vol. 2, no. 1, pp. 220-224, 2019.

[3] Aini, Nurul, and Nur Azizah. Teknologi Budidaya Tanaman Sayuran Secara Hidroponik. Universitas Brawijaya Press, 2018. 
[4] Marginingsih, Ratih Sri, Ary Susatyo Nugroho, and M. Anas Dzakiy. " Pengaruh Substitusi Pupuk Organik Cair Pada Nutrisi AB mix terhadap Pertumbuhan Caisim (Brassica juncea L) pada Hidroponik Drip Irrigation System." Jurnal Biologi dan Pembelajarannya 5.1. 2018: 44-51.

[5] M. Dwiyaniti, R. N. Wardhani, and T. Zen, "Desain Sistem Pemantauan Kualitas Air Pada Perikanan Budidaya Berbasis Internet Of Things Dan Pengujiannya," MULTINETICS, vol. 5, no. 2, pp. 57-61, 2019.

[6] L. Mawardi, "Sistem Monitoring Limbah Industri Rayon," in Seminar Nasional Teknik Elektro, 2020, vol. 5, no. 2, pp. 186-189.

[7] D. A. A. Novitasari and D. T. I. Nirmala, "Rancang Bangun Sistem Monitoring pada Limbah Cair Industri Berbasis Mikrokontroler dengan Antarmuka Website," Coding J. Komput. dan Apl., vol. 6, no. 3, 2018.

[8] Y. Rahmanto, A. Rifaini, S. Samsugi, and S. D. Riskiono, "Sistem Monitoring $\mathrm{pH}$ Air Pada Aquaponik Menggunakan Mikrokontroler Arduino UNO," J. Teknol. dan Sist. Tertanam, vol. 1, no. 1, pp. 23-28, 2020.

[9] Y. H. Putra and S. Dedi Triyanto, "Sistem Pemantauan Dan Pengendalian Nutrisi, Suhu, Dan Tinggi Air Pada Pertanian Hidroponik Berbasis Website," Coding J. Komput. dan Apl., vol. 6, no. 3, 2018.

[10] Sudana, Dhana, and Dadang Eman. " IoT Based: Hydroponic Using Drip Non-Circulation System for Paprika." 2019 International Conference of Artificial Intelligence and Information Technology (ICAIIT). IEEE, 2019. 